CARPATHIAN JOURNAL OF FOOD SCIENCE AND TECHNOLOGY

Journal home page: http://chimie-biologie.ubm.ro/carpathian_journal/index.html

\title{
IDENTIFICATION PARAMETERS FOR COMPARISON OF NATURALLY AND COMMERCIALLY LIME JUICE
}

\author{
Azadeh Bayati ${ }^{1}$, Firouzeh Nazari², Hassan Hassanzadazar', Mir-Jamal Hosseini ${ }^{3 凶}$ \\ ${ }^{1}$ Department of Food Safety and Hygiene, School of Public Health, Zanjan University of Medical \\ Sciences, Zanjan, Iran \\ ${ }^{2}$ Food and Drug Administration, Iran University of Medical Sciences, Tehran, Iran \\ ${ }^{3}$ Department of Pharmacology and Toxicology, School of Pharmacy, Zanjan University of Medical \\ Sciences, Zanjan, Iran. \\ 凶jamal_hossini@yahoo.com; mhosseini@zums.ac.ir \\ https://doi.org/10.34302/crpifst/2020.12.1.11 \\ Article history: \\ Received: \\ 13 December 2019 \\ Accepted: \\ 23 February 2020 \\ Keywords: \\ Lime Juice; \\ Adulteration; \\ Ion chromatography; \\ High performance liquid \\ chromatography (HPLC).

\section{ABSTRACT} \\ Public consumption of lemon and lime juice and its best-selling market \\ induces jobber to carry out numerous adulterations in order to reduce \\ production costs and thereby endangering people's health and create \\ numerous problems for the relevant regulatory authorities. It seems the \\ previous proposed parameters are not suitable and reliable for detection of \\ lime juice adulteration. In this regards, several important parameters as \\ cations, anions, citric acid and isocitric acid were studied for distinguish \\ between naturally and commercially Persian lime juices. For this purposed, \\ various cations $\left(\mathrm{Li}^{+}, \mathrm{Na}^{+}, \mathrm{NH}^{+}, \mathrm{K}^{+}, \mathrm{Ca}^{2+}\right.$ and $\left.\mathrm{Mg}^{2+}\right)$ and anion $\left(\mathrm{F}^{-}, \mathrm{Cl}^{-}, \mathrm{NO}_{2}\right.$, \\ $\mathrm{Br}^{-}, \mathrm{NO}_{3}{ }^{-}, \mathrm{PO}^{3-}$ and $\mathrm{SO}_{3}{ }^{2-}$ ) were investigated in naturally and commercially \\ lime juice using Ion chromatography system equipped with Suppressed \\ conductivity detector. Citric acid and isocitric acid were determined and \\ quantified using HPLC-UV detection. After optimization the method, linear \\ calibration curves were plotted. The average recoveries of the analytes were \\ higher than $72 \%$. Our results showed significant difference in cations $\left(\mathrm{Li}^{+}\right.$, \\ $\mathrm{Na}^{+}$and $\mathrm{K}^{+}$) and anion $\left(\mathrm{Cl}^{-}\right)$between natural and commercial lime juice \\ samples. The citric acid: isocitric acid ratio was found with a mean of 280 \\ \pm 86 in natural products, while this ratio was found with a mean of $503 \pm 149$ \\ in commercial products using HPLC method. This result shows that this \\ method would be useful for determining of routine adulteration in food \\ control laboratories. This is the first study for showing of real difference \\ between natural and commercial difference in lime juice consumed by \\ Iranian population.
}

\section{Introduction}

Lime is an evergreen hybrid fruit plant that belongs to the citrus family and contains acidic juice vesicles(Ikeda and Spitler 1964). There are various species of citrus trees whose fruits are called limes. Kaffir lime, West Indian lime, Persian lime, desert lime and sweet lime are some of the most common types of lime that vary in size, color and flavor(Liu et al. 2012; Saeidi et al. 2011). Among citrus fruits, limes are excellent sources of important nutrients including vitamin $\mathrm{C}$ and folate(Scherer et al. 2012).They also contain dietary fiber, and other bioactive components such as carotenoids and flavonoids, organic acid (e.g. citric acid) and mineral elements (e.g. potassium) involved in numerous health promoting properties(Silalahi 2002). Inorganic elements are vital and essential compounds to public health similar to vitamins and amino acids(Giacomo et al. 1974). As 
minerals need for regulating and building the body cells, transfer of chemical substances in and out of the cells, controlling in the composition of body fluid and cells(Lorente et al. 2014; Silalahi 2002). In Iran, limes are used, occasionally as a fresh fruit; generally, lime wedges and lime juice are served as a garnish to salads, or Iranian dishes (Saeidi et al. 2011).

Lime juice is one of the most popular flavors in Iran(Saeidi et al. 2011). Although most Iranians tended to use homemade lime juice in the past, but nowadays, commercially lime juice consumption is on the rise(Lorente et al. 2014). Popularity and the cost of the lime juice make it as target for adulteration(áJohn Dennis 1998). Food adulteration is committed in different ways including combining food with cheaper ingredients, concealing the quality, selling rotten food, replacing authentic ingredients with other ingredients and adding chemicals. Some forms of food adulteration are harmful like using industrial coloring and chemicals which put human health at risk such as tooth enamel damage and gastrointestinal symptoms(áJohn Dennis 1998; Álvarez et al. 2014; Lorente et al. 2014; Scherer et al. 2012; Uçan et al. 2016; Yamamoto et al. 2008).

Food adulteration in different parts of the world varies depend on geographic region, economic condition and social culture such as the other fruit juice, incidence of lime juice adulteration can be achieved easily through the addition of water, citric acid, colorants or other cheaper fruit juices or ingredients to the original fruit juice (Lorente et al. 2014; Muntean 2010; Scherer et al. 2012; Uçan et al. 2016).

It is known that the chemical composition of fruits such as lemon juice is variable according to many factors such as the variety of fruit, ripening stage, geographical location and horticultural practices. It is also known that in industry, the juices are commonly submitted to many legal processing practices such as thermal treatment, adding organic acids (generally citric acid) or sugar to adjust the flavor of the final product. The previous industrial practices can also change the chemical composition of the final product. Thus, we cannot consider all the types of difference in the chemical composition of the sample as an adulteration(Cautela et al. 2008; Fügel et al. 2005).

It was recently reported that the quantification and characterization of organic acids appear to be useful in estimating the amount of fruit and controlling the fruit authenticity. However, since organic acids are essential technological ingredients of most recipes, this analytical tool is not evidently applicable to jams and fruit preparations. Furthermore, depending on cultivar and degree of ripeness, organic acid contents are subject to considerable variations, which limits their applicability as a quantitative marker in fruit juices too (Fügel et al. 2005).

Unfortunately, sometimes the type of lime juice adulterations in Iran is different from developed countries such as full synthetic products which are harmful for popular health such as adding cheap fillers or additives, hiding food quality, misleading consumers by providing wrong information about the product or mislabeling, selling rotten food, (improper substitution) sometimes substitute harmful material instead of real ingredients(Saeidi et al. 2011).

Among regulatory systems, International Fruit Juice Union (IFU) has been specially developed and provided collection of chemical and microbiological methods for several fruit juices authenticity including lime(áJohn Dennis 1998; Cautela et al. 2008; Nuncio-Jáuregui et al. 2014; Zhang et al. 2009). Identification of lime juice adulteration is a complex issue which can be changed by adding a series of frauds via analytical methods, which can often be timeconsuming and cost effect(Álvarez et al. 2014; Cautela et al. 2008; Lorente et al. 2014; Muntean 2010; Nuncio-Jáuregui et al. 2014; Penniston et al. 2008; Robards et al. 1997; Saeidi et al. 2011; Scherer et al. 2012; Uçan et al. 2016). Since there is not robustness methods for detection of natural lime juice from commercial products in adulteration, we tested whether (a) is there reliable and suitable inorganic compound to able distinguish between natural and commercial lime juice (b) is the 
citric acid: isocitric acid ratio as satisfying and preferable factor between natural and commercial lemon juice difference (c) the acidification of lime juice can be help in comparison of natural from commercial lime juice.

Therefore, it investigated the concentration of mineral element and organic acid in commercial and natural citrus lime juice to find new markers for identification of natural from commercial lime juice products using by Ion Chromatography and High performance liquid chromatography (HPLC) methods.

\section{Materials and methods}

\subsection{Materials}

All solutions were prepared using analytical grade reagents and deionized water. Anions (Fluoride, Chloride, Bromide, Nitrite, Nitrate, Phosphate, Sulphite) and also cations (Lithium, Sodium, Potassium, Magnesium, Ammonium, Calcium and other chemicals or solvents were purchased from Merck (Darmstadt, Germany). All sample containers and glassware were thoroughly cleaned with $0.1 \mathrm{M} \mathrm{HCl}$ solution and then finally with deionized water.

\subsubsection{Samples}

The appropriate experimental plan in present study had to contain three categories of lemon juice samples: 1) natural sample which prepared from lemon juice samples from dilution of samples with deionized water $(1: 50 \mathrm{v} / \mathrm{v})$ and filtered $(0.45 \mu \mathrm{m})$ prior to analysis.; 2) Commercial sample which prepared from market collected samples; 3) In-laboratory adulterated lemon juice samples which can be prepared from fruit and different adulteration materials. Unfortunately, due to the lack of information on the preparation of adulteration materials which used in commercial lemon juice and following of persons which informed the percentage of fruit and different adulteration materials, it had not possible to investigate the third category of samples and omitted the difference in the chemical composition found between natural and commercial samples is related to the adulteration practices. Therefore, we decided to investigate only 2 categories of lemon juice samples in our investigation. The twenty samples (10 naturally lime juice compared to 10 commercial lime juices) were collected randomly from local supermarkets and convenient stores in different provinces of Iran (Dezphol, Astara, Jahrom, Lar, Bandarabas, Shiraz, Mazandaran, Zanjan, Tehran and etc). All the samples were stored at $4^{\circ} \mathrm{C}$ until analysis.

\subsubsection{Apparatus:}

The 881 Compact Ion chromatography system (Metrohm, Switzerland) equipped with Suppressed conductivity detector with Metrohm suppressor Module (MSM, $50 \mathrm{mmol} / \mathrm{L} \mathrm{H}_{2} \mathrm{SO}_{4}$ ). The MagIC net (version 2.3) software was used for monitoring system and data analysis. The ultrasonic bath was provided by Powersonic 405 from Daihan Lab Tech CO (Nanyangiu, Korea). Anion column metrosep A Supp 4 (size $250 \times 4.0$, pressure $8 \mathrm{M} \mathrm{Pa}$, cond $2 \mu \mathrm{s} / \mathrm{cm}$ ) and cationic column metrosep C $4(150 \times 4.0)$, pressure $7 / 5 \mathrm{M} \mathrm{Pa}$,cond $900 \mu \mathrm{s} / \mathrm{cm}$ ) was used for measurement of anions and cations involved in our samples.

A high-performance liquid chromatography system equipped with auto sampler (Waters 717), binary HPLC pump (Waters 1525), and a dual $\lambda$ absorbance UV detector (Waters 2487) was used for the analysis. The reverse-phase column was a Waters Capital 40 form $(20+20)$ $\mathrm{cm} \times 4.6 \mu \mathrm{m}, 4 \mu \mathrm{m}$ particle size (Waters, Milford, MA, USA) at $30{ }^{\circ} \mathrm{C}$. The mobile phase was composed of the $\mathrm{KH}_{2} \mathrm{PO}_{4}$ buffer $(0.01 \mathrm{M})$ that was filtered through a $0.45 \mathrm{~mm}$ membrane and degassed by a sonication process before use. The

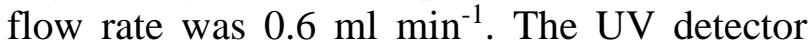
operated at wavelength of $270 \mathrm{~nm}$.

The injection volume for both standards and samples was $100 \mu$. The run time and retention times for citric acid and isocitric acid were $23.83 \pm 0.16 \mathrm{~min}$ and $15.52 \pm 0.02 \mathrm{~min}$, respectively. To evaluate the reliability of the results, in addition to applying the common validation assessment to the developed method, internal quality control experiments were also performed. Each working day, a blank and a spiked sample were also analyzed. Samples were spiked with citric acid and isocitric acid 
concentrations at desired levels and according to the recovery values, the results of citric acid and isocitric acid in the real samples were corrected.

\subsubsection{Standard, sample and solvent preparation}

Ion stock standard solutions were prepared in deionized water weekly and then these standards were used to prepare mixed standard for analysis. Working standard solutions were prepared daily by diluting the mix standard with deionized water. As sample was clear, no extraction and cleanup was needed .The samples were diluted 1:50 with deionized water to obtain a final volume of $50 \mathrm{ml}$ and filtered $(0.45 \mu \mathrm{m})$ prior to analysis. Mobile phase for determination of anions was made up of sodium hydrogen carbonate $\left(1.7 \mathrm{mmol} . \mathrm{L}^{-1}\right)$, sodium carbonate $(1.8$ mmol. $\left.\mathrm{L}^{-1}\right)$ and sulfuric acid $\left(1.8 \mathrm{mmol} . \mathrm{L}^{-1}\right)$ and sulfuric acid ( 50 mmol. $\left.\mathrm{L}^{-1}\right)$ with a flow rate of 1 $\mathrm{ml} / \mathrm{min}$. Selective mobile phase for cations was made up of nitric acid $\left(1.7 \mathrm{mmol} . \mathrm{L}^{-1}\right)$ and Dipicolinic acid $\left(0.7 \mathrm{mmol} . \mathrm{L}^{-1}\right)$ with a flow rate of $0.9 \mathrm{ml} . \mathrm{min}^{-1}$.

Citric acid and isocitric acid were determined and quantified using highperformance liquid chromatography chromatography-UV detection. This method has already been validated by Faroogh Life Sciences Research Laboratory as a part of National Research Project under Institute of Standards \& Industrial Research of Iran and in due course after successful validation by Interlaboratory Comparison mean shall be published as Iranian National Standard. Briefly, Sample preparation was done with adding of $50 \mu 1$ lime juice and $50 \mu 1$ internal standard (formic acid and acetic acid was used an internal standard (2 $\left.\mathrm{mg} \cdot \mathrm{ml}^{-1}\right)$. and diluted with water $(3 \mathrm{ml})$ and finally filtered $(0.45 \mu \mathrm{m})$ and degassed by a sonication process prior to analysis. Mobile phase for determination of citric acid and isocitric acid were $\mathrm{KH}_{2} \mathrm{PO}_{4}(0.01 \mathrm{M})$ with a flow rate of $0.6 \mathrm{ml} / \mathrm{min}$ at $30^{\circ} \mathrm{Cwith} \mathrm{UV}$ detector at wavelength of $270 \mathrm{~nm}$.

\subsubsection{Validation Procedure}

The validation process was done in suggested parameters: 1 . System suitability: The relative standard deviation (RSD) $\leq 3 \%$ from 5 consecutive injections of standard samples in different days. 2. Linearity: Employing five concentration levels for establishing of standard calibration curves with high value of the regression coefficient $\left(R^{2}>0.99\right)$.3. Precision and accuracy: based on three consecutive injections of ions at five desired concentration levels (intra-day and inter-day) via determining of recovery. 4. Limits of detection (LOD) and quantification $(L O Q)$ : The LOD and LOQ were estimated by signal-to-noise ratio, 3:1 and 10:1, respectively in samples.

\subsection{Statistical Analysis}

All statistical analyses were performed using the SPSS software (Window version 18) and Excel 2007 software. Results were presented as means \pm SD. Assays were performed in triplicate and the probability. Mann-Whitney test was applied for determining of significance in comparisons of two groups. The confidence level required for significance was set at $\mathrm{P}<0.05$.

\section{Results and discussions}

Adulteration of fruit juice is widespread issue which is become from 20-30 years ago due to no policing and economic reasons(áJohn Dennis 1998; Zhang et al. 2009). Besides, detection of fruit juice adulteration is very complicated; application of powerful method is needed. Unfortunately, there were no precise ingredient percentages of lemon juice for determination of natural products from adulterated samples due to relation of adulteration practices to geographical and biological effects(Fügel et al. 2005; Liu et al. 2012). On the other hands, we couldn't find any informed person which provide any data about the percentage and composition of lemon juice adulteration in present study or similar investigation.

Also, the chemical composition of limes affected by the variety of lime, ripening stage, geographical location and horticultural 
practices. Together, the limes in industry tolerated thermal treatment and adding of organic acids (especially citric acid) or sugar to adjust the flavor of the final product which changes the chemical composition (Ikeda and Spitler 1964; Lorente et al. 2014). Due to higher amount of citric acid in lime or fruit juice, determining of this organic acid singly is not suitable marker in determination of adulteration. But, the recent data suggested that isocitric acid which can be found in low concentration in lime juice produced by conversion of citric acid by aconitase and isocitrate dehydrogenase enzyme. Therefore, the ratio citric/isocitric acid could be serves as a reference index of authenticity using application of powerful method.
Therefore, it decided usage of ion chromatography as an effective tool in identifying the type of cations and anions that are readily available in common products and HPLC methods for identification of citric acid and isocitric acid as another confirmation criterion in distinguish of natural lime juice from commercially products. Our study showed type and concentration of specific minerals and organic acids found in fruit juice products are important profiles in identifying of lime juice adulteration in Iran which continue to be discussed.

Table 1. Determination of calibration curve range, LOQ, LOD and retention time of cations and anions parameters in lime juices

\begin{tabular}{|l|c|c|c|c|c|c|}
\hline Ions & $\begin{array}{c}\text { Concentration } \\
\text { range(ppm) }\end{array}$ & LOD & LOQ & $\begin{array}{c}\text { RT } \\
(\mathbf{m i n})\end{array}$ & $\begin{array}{c}\text { Recovery for } \\
\text { LL}^{\mathbf{2}} \mathbf{R S D} \%\end{array}$ & $\begin{array}{c}\text { Recovery for } \\
\text { HL }^{\mathbf{b}} \mathbf{R S D} \%\end{array}$ \\
\hline Cations \\
\hline $\mathbf{L i}$ & $0.0625-1$ & 0.02 & 0.0625 & 1.52 & $99 \pm 0.8$ & $90 \pm 7.3$ \\
\hline Na & $0.3125-5$ & 0.1 & 0.3125 & 2.4 & $99 \pm 6.4$ & $83 \pm 3.4$ \\
\hline NH4 & $0.3125-5$ & 0.1 & 0.3125 & 2.9 & $103 \pm 4$ & $89 \pm 10$ \\
\hline K & $1.25-20$ & 0.4 & 1.25 & 4.35 & $99 \pm 1.7$ & $102 \pm 6.04$ \\
\hline Ca & $0.125-2$ & 0.2 & 0.125 & 11.18 & $100 \pm 0.1$ & $100 \pm 9.1$ \\
\hline Mg & $0.625-10$ & 0.2 & 0.625 & 12.76 & $91 \pm 1.1$ & $74 \pm 0.09$ \\
\hline Anions & $1-16$ & 0.3 & 1 & 3.88 & $99 \pm 0.2$ & $102+3.8$ \\
\hline F & $1-24$ & 0.5 & 1.5 & 4.95 & $98 \pm 1.08$ & $91 \pm 3.2$ \\
\hline Cl & $1-24$ & 0.5 & 1.75 & 5.53 & $102 \pm 0.09$ & $73 \pm 1.2$ \\
\hline NO2 & $1.25-20$ & 0.4 & 1.25 & 6.48 & $91 \pm 5.8$ & $92 \pm 5.2$ \\
\hline Br & $2.5-40$ & 0.8 & 2.5 & 7.07 & $101 \pm 0.2$ & $102 \pm 4.02$ \\
\hline NO3 & $5-80$ & 2 & 5 & 10.19 & $87 \pm 3.5$ & $103 \pm 5.8$ \\
\hline PO4 & $1.25-20$ & 0.7 & 2 & 11.64 & $96 \pm 2.5$ & $99 \pm 1.9$ \\
\hline SO3 &
\end{tabular}

${ }^{\mathrm{a}}$ LL-Lowest validation level ; ${ }^{\mathrm{b}} \mathrm{HL}-$ highest validation level

\subsection{Analytical method performance in IC}

An external calibration curve was constructed using 5 standards for each of cations $\left(\mathrm{Li}^{+}, \mathrm{Na}^{+}, \mathrm{NH}^{+}, \mathrm{K}^{+}, \mathrm{Ca}^{2+}\right.$ and $\left.\mathrm{Mg}^{2+}\right)$ and anion $\left(\mathrm{F}^{-}, \mathrm{Cl}^{-}, \mathrm{NO} 2, \mathrm{Br}^{-}, \mathrm{NO}^{-}, \mathrm{PO}^{3}{ }^{-}\right.$and $\left.\mathrm{SO}^{2-}\right)$ in the satisfied range. The calibration curve was linear in determined concentration range with a correlation coefficient $\left(\mathrm{R}^{2}\right)$ greater than 0.99 .
The relative standard deviation (RSD) for each concentration examined was less than $5 \%$ in standard samples. The LOD and LOQ based on the signal-to-noise ratio were achieved and shown in Table.1. The recovery experiments were performed by spiking the blank samples at five determined levels based on standard concentration. This experiment was carried out 
with three replicates at each level. The results of the recovery experiments were between $90 \%$ in many of spiked samples except $\mathrm{Na}$ and $\mathrm{Mg}$ in spiked levels (0.3125 and $0.625 \mathrm{ppm})$ (Table.2). The RSD range of recoveries was less than $12 \%$ (Table.3). The chromatogram of mixed standard solution for anions and cations were shown in Figure.1A and Figure.1B. Retention time of lithium, sodium, ammonium, potassium, calcium and magnesium in the spiked samples were at $1.52,2.40,2.90,4.35,11.18$ and 12.76 min, respectively. Retention time for anions including fluoride, chloride, nitrite, bromide, nitrate, phosphate and solphite were $3.88,4.95$, 5.53, 6.48, 7.07, 10.19 and $11.64 \mathrm{~min}$, respectively. The chromatograms of standards (cations and anions), naturally and commercially lime juice (blank or real sample) and spiked sample in naturally samples are shown in Figure.1 (A to G).

Table.2. Level of cations and anions concentration in real and commercial lime juice Samples

\begin{tabular}{|c|c|c|c|}
\hline \multicolumn{3}{|c|}{ Ions amount $(\mathrm{ppm})$ in real samples $($ Mean \pm SD) } & \multirow[b]{2}{*}{$\mathrm{P}$ value-significant } \\
\hline Cations & Natural samples & Commercially samples & \\
\hline $\mathrm{Li}$ & $4.43 \pm 2.6 * * *$ & ND & $\mathrm{P}<0.001$ \\
\hline $\mathrm{Na}$ & $46.5 \pm 43.2 * *$ & $701.28 \pm 625.8$ & $\mathrm{P}=0.004 ; \mathbf{P}<\mathbf{0 . 0 1}$ \\
\hline $\mathrm{NH}_{4}$ & $143.6 \pm 63.6$ & $272.6 \pm 267.8$ & $\mathrm{P}=0.156 ; \mathrm{P}>0.05$ \\
\hline $\mathrm{K}$ & $191 \pm 54.1 *$ & $103.2 \pm 83$ & $\mathrm{P}=0.012 ; \mathbf{P}<\mathbf{0 . 0 5}$ \\
\hline $\mathrm{Ca}$ & $42.7 \pm 28.6$ & $25.8 \pm 24.6$ & $\mathrm{P}=0.174 ; \mathrm{P}>0.05$ \\
\hline $\mathrm{Mg}$ & $6 \pm 4.8$ & $6 \pm 6.2$ & $\mathrm{P}=1 ; \mathrm{P}>0.05$ \\
\hline \multicolumn{4}{|l|}{ Anions } \\
\hline $\mathrm{F}$ & $79.4 \pm 41.5$ & $55.2 \pm 40.11$ & $\mathrm{P}=0.201 ; \mathrm{P}>0.05$ \\
\hline $\mathrm{Cl}$ & $104 \pm 41 *$ & $322.7 \pm 254.7$ & $\mathrm{P}=0.015 ; \mathrm{P}<\mathbf{0 . 0 5}$ \\
\hline $\mathrm{NO}_{2}$ & $2.3 \pm 2.03 *$ & ND & $\mathrm{P}=0.027 ; \mathrm{P}<\mathbf{0 . 0 5}$ \\
\hline $\mathrm{Br}$ & $13.8 \pm 23.4$ & $5.8 \pm 14.7$ & $\mathrm{P}=0.372 ; \mathrm{P}>0.05$ \\
\hline $\mathrm{NO}_{3}$ & $60.5 \pm 50.1$ & $38.3 \pm 25.5$ & $\mathrm{P}=0.228 ; \mathrm{P}>0.05$ \\
\hline $\mathrm{PO}_{4}$ & $1153.5 \pm 1026.2^{*}$ & $298.7 \pm 347.8$ & $\mathrm{P}=0.023 ; \mathrm{P}<\mathbf{0 . 0 5}$ \\
\hline $\mathrm{SO}_{3}$ & $133.7 \pm 240.4$ & $611.5 \pm 968.3$ & $\mathrm{P}=0.147 ; \mathrm{P}>0.05$ \\
\hline
\end{tabular}

Table 3. Determination of calibration curve range, LOQ, LOD and retention time of citric acid, isocitric acid, formic acid \& acetic acid in lime juices

\begin{tabular}{|c|c|c|c|c|}
\hline Organic acid & $\begin{array}{c}\text { Concentration range } \\
\left(\mathbf{m g . m l ^ { - 1 } )}\right.\end{array}$ & LOQ & LOD & $\begin{array}{l}\text { Retention time } \\
(\text { Mean } \pm \text { SD })\end{array}$ \\
\hline Citric acid & $0.125-1.5$ & 40 & 12.5 & $23.83 \pm 0.16$ \\
\hline Isocitric acid & $0.00125-0.05$ & 0.5 & 0.017 & $15.52 \pm 0.02$ \\
\hline Formic acid & 2 & --- & --- & $13.19 \pm 0.01$ \\
\hline Acetic acid & 2 & --- & --- & $18.79 \pm 0.01$ \\
\hline
\end{tabular}

Table.4. Level of Citric acid, Isocitric acid concentration and Citric: isocitric acid ratio in real and commercial lime juice samples

\begin{tabular}{|c|c|c|c|}
\hline $\begin{array}{c}\text { Lemon juice } \\
\text { Samples }\end{array}$ & Citric acid(mg/ml) & Isocitric acid(mg/ml) & Citric/isocitric acid \\
\hline Natural & $69.7 \pm 4.09$ & $0.273 \pm 0.09$ & $279.93 \pm 85.85$ \\
\hline Commercial & $67.02 \pm 5.52$ & $0.143 \pm 0.03 * * *$ & $503.3 \pm 148.55^{* * *}$ \\
\hline \multirow{2}{*}{ Com* Compared with between groups }
\end{tabular}




\section{Figure.1. IC Chromatograms of a:}

A. Cation Standard including Li (0.5 ppm), Na (2.5 ppm), NH4 (2.5 ppm), K(10 ppm), Ca(1 ppm) and Mg(5 ppm)

B. Anion Standard including F (8 ppm), $\mathrm{Cl}(12 \mathrm{ppm}), \mathrm{NO}_{2}(14 \mathrm{ppm}), \mathrm{Br}(10 \mathrm{ppm}), \mathrm{NO}_{3}(20 \mathrm{ppm}), \mathrm{PO}_{4}(40 \mathrm{ppm})$ and $\mathrm{Mg}(10 \mathrm{ppm})$

C. Cations in real or blank sample in natural lime Juice

D. Anions in real or blank sample in natural lime Juice

E. Cations in real or blank sample in Commercially lime juice

F. Anions in real or blank sample in Commercially lime juice

G. Spiked Sample
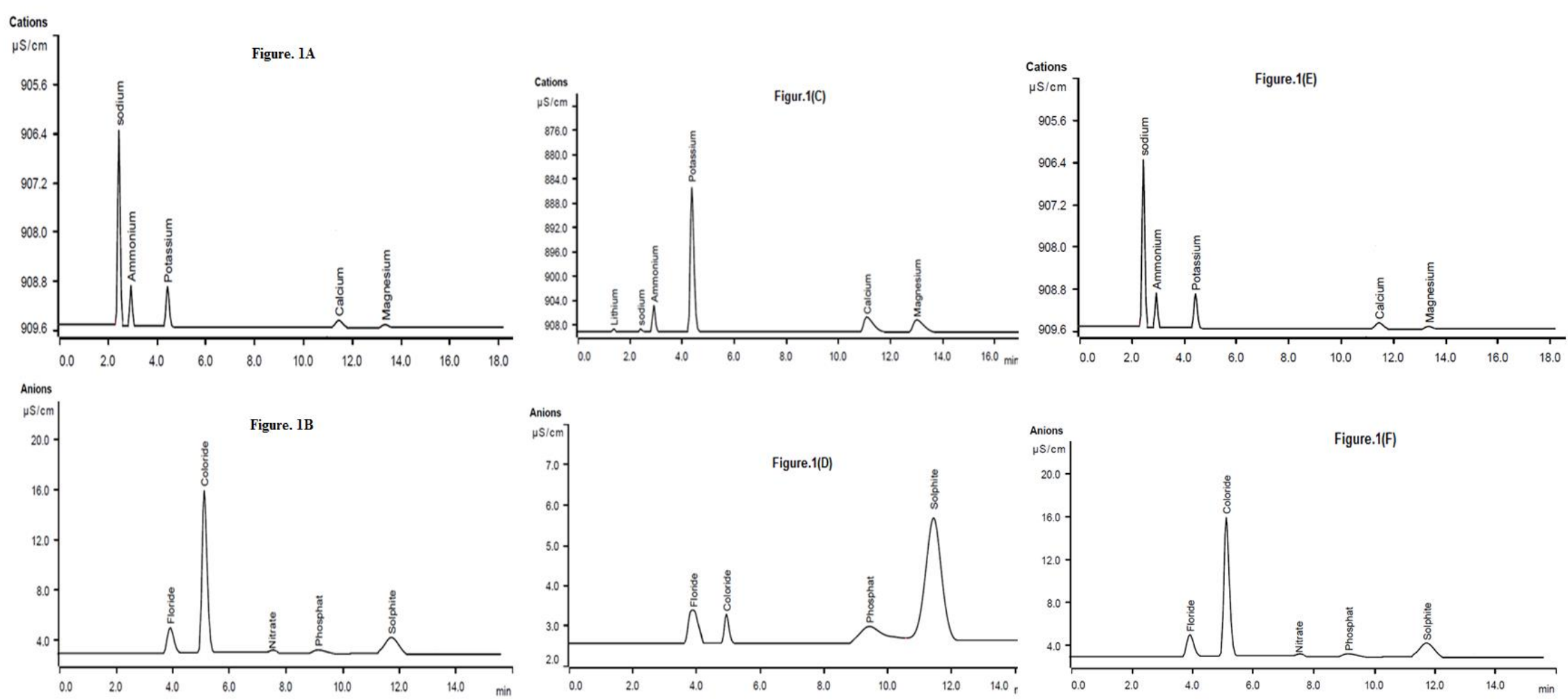


\subsection{Amount of ions in lime juice}

The obtained results of ions (cations and anions) concentrations in naturally fresh and commercially lime juice are shown in Table 4. Our finding indicated that the investigated anions ( $\mathrm{Li}, \mathrm{Na}, \mathrm{NH}^{+}, \mathrm{Ca}, \mathrm{K}, \mathrm{Mg}$ ) and cations $\left(\mathrm{F}, \mathrm{Cl}, \mathrm{NO}_{2}, \mathrm{Br}, \mathrm{NO}_{3}, \mathrm{PO}_{4}, \mathrm{SO}_{3}\right.$ ) were detected in all of the naturally fresh lime juice samples. The t-test analysis showed that there was significant difference $(\mathrm{p}<0.05)$ between mean levels of the lithium, sodium, potassium and chloride ions. Besides, our results confirmed that lithium and nitrite were found in all of natural samples without no observation in all commercial lime juice samples $(\mathrm{P}<0.05)$ as the specific difference between two groups of lime juice samples (natural and commercially).

The level of lithium in all commercial lime juice samples was below the LOD which was found in all of naturally lime juice products in the range of $4.43 \pm 2.6 \mathrm{ppm}$. The lowest and highest level of Lithium in naturally products was observed in the samples collected from Bandarabas (1.41ppm) and Mazandaran (9.99 ppm), (Data not shown). It seems that level of lithium in lime juice can be used as identical marker between naturally and commercial lime juice in Iran.

Based on our results, sodium was detected in all of the analyzed samples (naturally and commercially lime juice. The mean concentration level of sodium in naturally and commercially limes juice samples were $47 \pm 43$ and $701 \pm 625 \mathrm{ppm}$, respectively (Table.2). The $\mathrm{P}$ value less than 0.05 showed the significant difference between means of sodium level in lime juice is another identifiable marker similar to lithium in natural and commercial lime juice adulteration in Iran.

The highest level of sodium in natural and commercial products were observed in the samples collected from Bandarabas (123ppm) and Semnan (1915 ppm), respectively (Data not shown). Also, the highest level of potassium in natural and commercial lime juice were observed in the samples collected from Mazandaran (236ppm) and Esfahan (215ppm) respectively. The highest levels of Chloride in natural and commercial products were observed in the samples collected from Bandarabas (176ppm) and Esfahan (662 ppm) respectively.

Figure.2.(A)
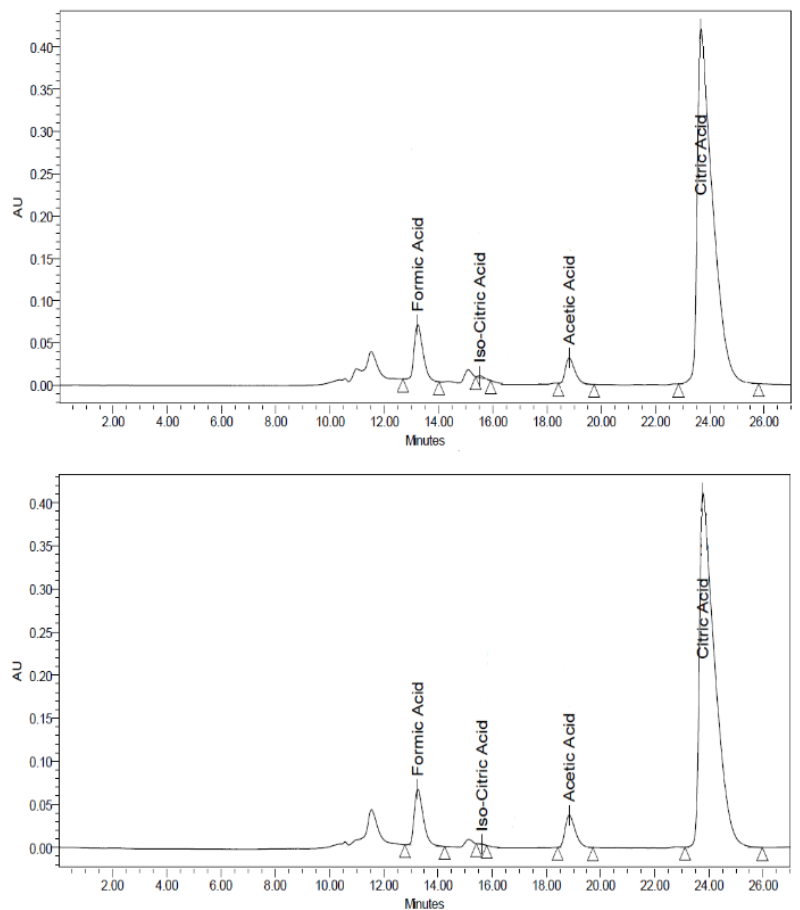

Figure.2.(B)

Figure.2. HPLC Chromatograms of a: Organic acids (citric acid and isocitric acid) in natural lime juice (A) and commercially lime juice (B). Acetic acid $(2 \mathrm{mg} / \mathrm{ml})$ and acid formic $(2 \mathrm{mg} / \mathrm{ml})$ were used as internal standard

\subsection{Citric: isocitric acid ratio in naturally and commercially lime juice by HPLC methods}

Organic acids such as acetate, lactate, citrate and isocitrate are caused by biological activity as good indicator of an old juice that may be too spoiled for consumption. The calibration curve range, LOQ, LOD and retention time of citric acid, isocitric acid, formic acid \& acetic acid in lime juices are summarized in Table.3. The average retention times were less than 16 and 24 min for isocitric acid and citric acid, respectively. In this regards, levels of citric acid, isocitric acid and their ratio in the lime juice samples were calculated. In this regards, levels 
of citric acid, isocitric acid and their ratio in the lime juice samples were was calculated. Although, the mean levels of citric acid in naturally and commercially lime juice had no significant difference $(\mathrm{p}>0.05)$, the mean level of isocitric acid and citric acid: isocitric acid ratio in naturally and commercially lime juice were significantly different (Table.5; $\mathrm{P}<0.001$ ). The HPLC chromatograms of the naturally and commercially lime juice samples by HPLC methods are shown in Figure.2.

\section{Conclusions}

Based on the present study, lime juice samples are significantly different in their chemical properties. Lime juice adulteration can't be detected just by measuring one or several chemical properties. However, LC-MS data that includes both chromatographic and mass spectrometric information, 100\% lime juice samples were successfully differentiated from adulterated samples containing 30\% lime juice. The findings show that this method allows rapid and accurate monitoring of citrus juices and getting more information on quality and possible adulteration of the product. Similar procedures could be used to monitor other fruit juices and quantitative diverse juice blends.

\section{References}

Ájohn Dennis, M.(1998). Recent developments in food authentication. Analyst 123(9), 15156.

Álvarez, J., S. Pastoriza, R. Alonso-Olalla, C. Delgado-Andrade and J. Rufián-Henares. 2014. Nutritional and physicochemical characteristic of commercial spanish citrus juices. Food chemistry 164, 396-405.

Cautela, D., B. Laratta, F. Santelli, A. Trifirò, L. Servillo and D. Castaldo. 2008. Estimating bergamot juice adulteration of lemon juice by high-performance liquid chromatography (hplc) analysis of flavanone glycosides. Journal of agricultural and food chemistry 56(13), 5407-14.

Fügel, R., R. Carle and A. Schieber. 2005. Quality and authenticity control of fruit purées, fruit preparations and jams-a review. Trends in Food Science \& Technology 16(10): 433-41.

Giacomo, A.D., U. Leuzzi and G. Micali. 1974. Amino acids of lemon juice. Essenze Deriv Agrum 44, 242-53.

Ikeda, R.M. and E.M. Spitler. 1964. Composition of citrus oils, isolation, identification, and gas chromatographic estimation of some esters and alcohols of lemon oil. Journal of agricultural and food chemistry 12(2), 114-17.

Liu, Y., E. Heying and S.A. Tanumihardjo. 2012. History, global distribution, and nutritional importance of citrus fruits. Comprehensive Reviews in Food Science and Food Safety 11(6), 530-45.

Lorente, J., S. Vegara, N. Martí, A. Ibarz, L. Coll, J. Hernández, M. Valero and D. Saura. 2014. Chemical guide parameters for spanish lemon (citrus limon (1.) burm.) juices. Food chemistry 162, 186-91.

Muntean, E. 2010. Simultaneous carbohydrate chromatography and unsuppressed ion chromatography in detecting fruit juices adulteration. Chromatographia 71(1), 6974.

Nuncio-Jáuregui, N., Á. Calín-Sánchez, F. Hernández and Á.A. Carbonell-Barrachina. 2014. Pomegranate juice adulteration by addition of grape or peach juices. Journal of the Science of Food and Agriculture 94(4), 646-55.

Penniston, K.L., S.Y. Nakada, R.P. Holmes and D.G. Assimos. 2008. Quantitative assessment of citric acid in lemon juice, lime juice, and commercially-available fruit juice products. Journal of Endourology 22(3), 567-70.

Robards, K., X. Li, M. Antolovich and S. Boyd. 1997. Characterisation of citrus by chromatographic analysis of flavonoids. Journal of the Science of Food and Agriculture 75(1), 87-101.

Saeidi, I., M.R. Hadjmohammadi, M. Peyrovi, M. Iranshahi, B. Barfi, A.B. Babaei and A.M. Dust. 2011. Hplc determination of hesperidin, diosmin and eriocitrin in iranian 
lime juice using polyamide as an adsorbent for solid phase extraction. Journal of pharmaceutical and biomedical analysis 56(2), 419-22.

Scherer, R., A.C.P. Rybka, C.A. Ballus, A.D. Meinhart, J. Teixeira Filho and H.T. Godoy. 2012. Validation of a hplc method for simultaneous determination of main organic acids in fruits and juices. Food chemistry 135(1), 150-54.

Silalahi, J. 2002. Anticancer and health protective properties of citrus fruit components. Asia Pacific Journal of Clinical Nutrition 11(1): 79-84.

Uçan, F., E. Ağçam and A. Akyildiz. 2016. Bioactive compounds and quality parameters of natural cloudy lemon juices. Journal of food science and technology 53(3), 1465-74.

Yamamoto, A., M. Kawai, T. Miwa, T. Tsukamoto, S. Kodama and K. Hayakawa. 2008. Determination of adulteration in apple juice by hplc with novel optical rotation detector. Journal of agricultural and food chemistry 56(16), 7302-04.

Zhang, Y., D. Krueger, R. Durst, R. Lee, D. Wang, N. Seeram and D. Heber. 2009. International multidimensional authenticity specification (imas) algorithm for detection of commercial pomegranate juice adulteration. Journal of agricultural and food chemistry 57(6), 2550-57.

\section{Acknowledgment}

This work was supported by the deputy of research of Zanjan University of Medical Sciences (Grant NO: A-11-769-11). We express our gratitude to Dr. Shojaee and Dr. karmi of Faroogh Life Sciences Research Laboratory for their skillful support in analysis of Citric and isocitric acid. 